\title{
ALGUNAS NOTAS SOBRE EL JURADO. EN DEFENSA DEL ESCABINADO
}

ENRIQUE ARNALDO ALCUBILLA

Letrado de las Cortes Generales

Vocal del Consejo General del Poder Judicial 


\section{SUMARIO}

I. Origen y evolución en Europa: del Jurado que resuelve sobre los hechos AL ESCABINADO. II. El JURAdO EN LA CONSTITUCIÓN DE 1978. III. LA OPCIÓN POR EL Jurado puro en la Ley Orgánica 5/1995, de 22 de mayo. IV. El funcionamiento del modelo de Jurado puro. El informe del Consejo General del Poder Ju-

dicial, V. Consideraciones finales. Nota bibloggráfica. 


\section{ALGUNAS NOTAS SOBRE EL JURADO. EN DEFENSA DEL ESCABINADO*}

POR

\section{ENRIQUE ARNALDO ALCUBILLA}

Letrado de las Cortes Generales

Vocal de Consejo General del Poder Judicial

\section{ORIGEN Y EVOLUCIÓN EN EUROPA: DEL JURADO QUE RESUELVE SOBRE LOS HECHOS AL ESCABINADO}

La polémica entre juradistas y antijuradistas constituye un apasionante episodio de la historia jurídica de los dos últimos siglos, particularmente desde el momento en que trasvasa el Canal de la Mancha y llega al continente. Ahora bien se articula en Francia, del mismo modo que en Inglaterra, exclusivamente para el enjuiciamiento de los hechos correspondiendo al juez resolver la cuestión de derecho en caso de condena. Sobre esta base Gaston de Bourge construye la definición clásica del Jurado -siempre circunscrito al ámbito penalcomo «la reunión de un cierto número de ciudadanos que no pertenecen a la clase de jueces profesionales y que son llamados por la ley para concurrir transitoriamente a la administración de justicia haciendo declaraciones que se llaman veredictos, según su convicción íntima sobre los hechos sometidos a su consideración". Son, pues, jue-

- Conferencia pronunciada en el Curso de Verano de la UNED (Ávila, 1998)) sobre "El Poder Judicial a debate», dirigido por Antonio TORRES DEL MORAL. 
ces temporales para el asunto sometido a su consideración, jueces legos en cuanto no juristas que resuelven según su convicción personal, jueces que actúan en colegio de forma autónoma y separada del juez profesional, $y$, por fin, jueces del hecho $y$ no del derecho, pues -como aseguró Montesquieu- dado que el «pueblo no es jurisperito, preciso es presentarle un hecho, un solo hecho, y que sólo atienda a esto, si debe absolver o condenar".

Este modelo pervive en Europa continental hasta bien avanzado el siglo $X X-y$ persiste únicamente en Bélgica, Suecia y el Reino Unido, en donde nació- en que es sustituido por otro notablemente más perfeccionado, ante la siempre difícil distinción beccariana entre el hecho $y$ el derecho, cual es el escabinado en el que los miembros del jurado se reúnen, deliberan y resuelven conjuntamente con los jueces técnicos. No existe ya un colegio autónomo de jueces legos, ni una resolución autónoma en forma de veredicto sobre los hechos, sino un único tribunal en el que se reúnen los escabinos y los jueces técnicos que adopta una resolución en forma de sentencia absolutoria o de condena. Como exponen con acierto Gutiérrez-Alviz y Moreno Catena (Comentarios a las Leyes Políticas. Edersa. Madrid, 1987) en el jurado "se ha ido operando una lenta y beneficiosa evolución hacia otras fórmulas" demostrando que el jurado no es una institución estereotipada sino que va evolucionando en el tiempo como consecuencia de las distintas exigencias sociales, fórmulas que se concreten básicamente en torno al escabinado que se ha impuesto -como se impuso en España con la Ley de 27 de julio de 1933- en Francia, Italia, Alemania, Suiza o Austria. Conforme a este modelo los jueces populares no conocen ya únicamente de los hechos, sino de la aplicación de las normas jurídicas, formando colegio con los jueces profesionales y elaborando de consenso la sentencia, en cuya deliberación y votación coparticipan.

\section{EL JURADO EN LA CONSTITUCIÓN DE 1978}

Tras una historia quebrada al socaire de las vicisitudes políticas, llena de establecimientos y derogaciones, de restauraciones y extinciones, resurge el jurado en la Constitución de 1978. Sin posibles apelaciones a la tradición ni al mejor funcionamiento de la Administración de Justicia, el constituyente de 1978 -tras cerrar distintas vías de participación política directa de los ciudadanos, por el temor a hipotéticos efectos negativos sobre la democracia representativa y sobre los partidos políticos- dejó abierta ésta de una forma genérica. No se configura la institución del jurado como una fórmula alternativa de justicia sino 
como la que permite o posibilita la participación popular en la Administración de Justicia con la extensión y conforme al procedimiento que la ley establezca. El artículo 125 de la Constitución parece así reflejarlo: "Los ciudadanos podrán ejercer la acción popular y participar en la Administración de Justicia mediante la institución del Jurado, en la forma y con respecto a aquellos procesos penales que la ley determine".

La simple lectura del precepto permite concluir que no contiene el artículo 125 una declaración programática sino un mandato al legislador para que module y concrete el derecho que se reconoce a los ciudadanos a participar en la Administración de Justicia, como a ejercer la acción popular. Si el constituyente impone, con fundamento en el origen popular de la justicia (artículo 117) como de todos los poderes del Estado (artículo 1.2), la institución del jurado, quiérese decir que el legislador no puede decidir sobre la participación de los ciudadanos en la Administración de Justicia mediante el jurado. El ámbito de libre configuración del legislador -que queda obligado a garantizar dicho derecho cívico- se concreta, como dispone in fine el artículo 125, en la determinación de "la forma" y alcance ("con respecto a aquellos procesos penales»).

Se circunscribe así el jurado a la justicia penal, reduciendo el ámbito de competencia con el que lo previó la Constitución de 1931, en la que no concibe el constituyente que pueda alcanzar a convertirse en un sistema alternativo al juez profesional sino que ha de manifestarse en algunos procesos penales determinados, pues, así lo reiteramos, el artículo 125 regula un derecho cívico, una concreción del status activus civitatis, pero no configura un nuevo modelo de Administración de Justicia, pues el artículo 117.1 determina que "La justicia emana del pueblo y se administra en nombre del Rey por Jueces y Magistrados integrantes del Poder Judicial, independientes, inamovibles, responsables y sometidos únicamente al imperio de la ley", correspondiendo a la Ley Orgánica del Poder Judicial determinar «el estatuto jurídico de los Jueces y Magistrados de carrera que formarán un cuerpo único» (artículo 122.1). El jurado queda, pues circunscrito a un ámbito reducido de la justicia penal, pues la Constitución no lo concibe para el conocimiento de todas las causas penales, teniendo en cuenta por lo demás que la administración de la justicia es atribuida a los jueces y magistrados de carrera que integran el Poder Judicial.

Al legislador corresponde asimismo definir la forma, es decir, el modelo o sistema de jurado. Aunque a la vista de la experiencia de los países de nuestro entorno que tanto tomó en cuenta al regular otras instituciones, la Constitución de 1978 pudo prever si hacía suyo el llamado sistema anglofrancés que distingue el juez de hecho del juez de 
derecho o el del escabinado, optó por atribuir esta decisión al legislador para el que a priori habría de quedar vedado el modelo de jurado puro desde el punto y hora que no se excepcionó la regla de motivación de las sentencias (artículo 120.3).

\section{LA OPCIÓN POR EL JURADO PURO EN LA LEY ORGÁNICA 5/1995, DE 22 DE MAYO}

Durante diecisiete años el legislador evitó o retrasó su puesta en marcha, quizás convencido de los problemas que comportaba en una organización judicial deficientemente estructurada o persuadido ante la contundencia de las razones expuestas, entre otros, por Alcalá Zamora en 1980 ("A propósito del Jurado". Boletín del llustre Colegio de Abogados de Madrid núm. 3) sobre su mal funcionamiento en distintos países. Durante esos diecisiete años se ha producido una abundante literatura jurídica en la que -con la excepción de Serrano Alberca (Comentarios a la Constitución. Cívitas. Madrid, 1985) y de la proposición de ley orgánica presentada en 1983 por el Grupo Vasco en el Congreso de los Diputados defensores de la distinción entre el juez de hecho y el juez de derecho- llama la atención la unanimidad en la defensa de la instauración del escabinado partiendo de la inescindibilidad del hecho y el derecho y de la exigencia constitucional de la motivación de las sentencias.

Así se han expresado, entre otros, Fairén Guillén, Gimeno Sendra, Pedraz Penalva, Pérez-Cruz, Montero Aroca, Gómez-Colomer, Soriano Díaz o Prieto-Castro (vid. nota bibliográfica), que recuerdan que en el escabinado han confluido la práctica totalidad de los ordenamientos jurídicos europeos. Gimeno Sendra («El artículo 125 de la Constitución", en Constitución y proceso. Tecnos. Madrid, 1988) apela asimismo a que en el escabinado se evita el predominio del juicio emocional y se solucionan los problemas del desconocimiento de los legos, y defiende, dada su carestía, su limitación a los delitos graves. Gutiérrez-Alviz y Moreno Catena (op. cit.) consideran también más ajustada la instauración del tribunal de escabinos, como figura evolucionada del jurado tradicional, a través del que se permite la participación directa de los ciudadanos en la Administración de Justicia, el contacto inmediato del pueblo y su Justicia, y una corresponsabilidad cívica en las tareas juzgadoras, sin que se aprecien mayores riesgos o peligros de la presunta influencia o incluso dominio de los jueces técnicos en los escabinos ante su mayor autoridad y conocimientos jurídicos pues los legos aportan otros criterios de conocimiento, valoración y crítica complementarios en el juicio. Como de manera concluyente expone Martín 
Ostos («Algunas consideraciones sobre el Jurado». Anuario Facultad de Derecho de la Universidad de Extremadura núm. 3) el escabinado ofrece la particularidad de no introducir diferencias entre diversas formaciones, al atribuir toda la labor de valoración, apreciación, calificación y decisión a un colectivo jurisdiccional único, compuesto tanto por magistrados profesionales y peritos en derecho como por ciudadanos posiblemente legos en conocimientos jurídicos; de esta manera se supera la problemática relativa a la posibilidad de valoración separada del hecho y el Derecho, a la vez que se acude a un organismo más reducido en número $y$ en el que resulta una constante la estrecha relación entre los jueces profesionales y los legos. En fin, en el tribunal de escabinos no hay dos declaraciones, una sobre los hechos a la vista de las pruebas $y$ otra sobre calificación de los hechos y aplicación del derecho, sino una única declaración sobre la cuestión.

Sólo en sentido contrario se han expresado López-Muñoz y Larraz ( Decálogo del Jurado español». Revista General de Derecho núm. 511, 1987), Marín Gámez (Elementos para una revisión crítica del Jurado en España. UNED. Jaén, 1997) y Martín Pallín (Manual del Jurado. El Consultor de los Ayuntamientos. Madrid, 1996). Como este último señala en la introducción a la obra citada si el protagonismo va a corresponder a los ciudadanos que forman parte del jurado es más coherente dejar que éstos deliberen en solitario bajo la fórmula del llamado jurado puro -que, por cierto, en Italia era considerado inconstitucional en cuanto supone ir más allá de la participación popular en la Administración de Justicia- y que los jueces profesionales controlen, dirijan y orienten el debate preliminar que tiene lugar en el momento del juicio oral. Con indisimulado voluntarismo se defiende la opción más apartada de la voluntas constituens, de la cultura jurídica occidental, y la más compleja en su conformación, pero que adquiere carta de naturaleza a través de la Ley Orgánica 5/1995, de 22 de mayo, del Tribunal del Jurado (en adelante LOTJ), modificada inmediatamente por la Ley Orgánica 8/1995, de 16 de diciembre, que circunscribe la competencia objetiva del mismo a una "lista de delitos": delitos contra las personas, delitos cometidos por funcionarios públicos en el ejercicio de sus cargos, delitos contra el honor, delitos contra la libertad y la seguridad, y delitos de incendios; $e$ incluso dispone que valorará a la vista de la experiencia y de la consolidación de la institución, la ampliación progresiva de los delitos que han de ser objeto de enjuiciamiento.

Conforme a la LOTJ -el jurado está formado por nueve miembros y presidido por un magistrado de la Audiencia Provincial- decide a través de la emisión del veredicto sobre tres cuestiones: 
- participación de los acusados en relación con los hechos que les sean imputados, declarando probado o no el hecho justiciable, incluyendo la participación efectiva y las circunstancias modificativas de la responsabilidad criminal.

- declaración de culpabilidad o inocencia de cada uno de los acusados en relación con el delito o delitos imputados.

- declaración sobre la eventualidad de aplicar, al declarado culpable, los beneficios de la remisión condicional de la pena que se le impusiere para el caso de que concurran los presupuestos legales al efecto, así como sobre la petición o no de indulto.

\section{EL FUNCIONAMIENTO DEL MODELO DE JURADO PURO. EL INFORME DEL CONSEJO GENERAL DEL PODER JUDICIAL}

Transcurrido el periodo de vacatio legis de seis meses, a fin de que el Ministerio de Justicia proveyese los medios materiales precisos y de modo no menos importante el Consejo General del Poder Judicial dispusiera de los de formación de jueces y magistrados, el jurado ha empezado a funcionar en España, dieciocho años después de la aprobación de la Constitución, ciertamente con no pocas reticencias de los expertos ante el modelo elegido y ante una moderada inquietud de la opinión pública (un $38,9 \%$ se muestra en contra del jurado, según datos del $\mathrm{CIS}$ de abril-mayo de 1997) que contempla con recelo la consagración como deber inexcusable de la participación en este instituto (un $41,2 \%$ asegura que le disgustaría muchos formar parte del jurado y un $25,4 \%$ que más bien le disgustaría, según dicha encuesta). Lo más relevante del jurado es su propia existencia en cuanto manifestación de la participación ciudadana en la justicia penal, de la que aunque no cabe predicar su necesariedad no debe olvidarse que responde a un imperativo constitucional.

Las dudas perviven, e incluso se alimentan periódicamente a la vista de determinados veredictos "sorprendentes" o "sorpresivos", y no transcurre un breve lapso temporal sin oír nuevas voces en pro de la reforma de la Ley del Tribunal del Jurado, cuyas deficiencias técnicojurídicas han sido ampliamente resaltadas. Incluso un decidido partidario del modelo de jurado puro como Marín Gámez (op. cit.) señaló que: "La Ley del Jurado vigente, hoy duramente contestada, tiene innegables defectos. La reinstauración del jurado es una realidad precisada de perfeccionamiento después de un breve rodaje».

Carece de sentido, en cualquier caso, reactualizar el debate entre juradismo y antijuradismo, dada la dicción constitucional; como dema- 
gógica resulta la vinculación entre la existencia del jurado y la solución de los problemas de la Administración de Justicia. Pero, y en contradicción con el gradualismo y la prudencia de que hizo gala la Ley Orgánica de 1985, la regulación de la institución exige una revisión en profundidad que resuelva las imperfecciones y las rigideces de que adolece, lo que pasa necesariamente por el cambio de modelo en pro del escabinado, superior técnicamente y mediante el que se resolverían las perturbaciones que genera en la justicia penal el jurado puro. Estas son nítidamente subrayadas en los informes sobre la aplicación de la Ley del Jurado que han aprobado el Consejo General del Poder Judicial y la Fiscalía General del Estado, cuyo origen se encuentra en la proposición de ley aprobada por el Pleno del Congreso de los Diputados el 22 de abril de 1997 para que a la vista de los mismos el Gobierno "valore la oportunidad de impulsar una posible reforma de la misman. Nos detenemos en el primero de ambos, elaborado conforme a un método empírico e inductivo consistente en el examen detallado de un total de 76 causas, la totalidad de las seguidas ante el Tribunal del Jurado desde su implantación hasta el 31 de marzo de 1997, con un porcentaje nada anecdótico de "veredictos sorprendentes" (gran interés reviste el análisis que sobre este informe efectúa E. Pedraz-Penalva. "Sobre la participación popular en la justicia penal". Revista Canaria de Ciencias Penales, núm. 4, 1999).

Uno de los primeros aspectos que se cuestionan es la delimitación del ámbito competencial del jurado, concluyendo, que determinados delitos de menor entidad, por causar disfunciones en la práctica, deberian sustraerse del procedimiento del jurado. También se sugiere la aplicación de las reglas ordinarias de conexidad procesal frente a las reglas especiales que prevé la LOTJ, pues las vigentes comportan la atribución al conocimiento del jurado de delitos que el legislador dejó inicialmente al margen de su jurisdicción. Asimismo, merecen observaciones críticas algunos aspectos procesales de la fase de instrucción y de la fase intermedia de este procedimiento como son la excesiva duración de la primera o los problemas que suscita el planteamiento de algunas cuestiones previas en la segunda.

En cuanto a la función del magistrado-presidente del Tribunal del Jurado presenta dificultades el que éste no disponga del sumario, y se apunta como solución la exigencia a las partes de que especifiquen en la proposición de prueba el objeto preciso de las que se proponen. Se critica asimismo la gran rigidez formal en la redacción del auto de hechos justiciables, cuando sería más conveniente una mayor flexibilidad que permitiera destacar aquellas consideraciones del hecho injusto 
que son realmente trascendentes para la calificación de los hechos y posterior pronunciamiento del jurado. Cabe añadir también el problema generado como consecuencia de la instauración por la ley de dos momentos tendentes a la valoración de la prueba y a su vez dos órganos diferentes para tal cometido, de suerte tal que el artículo 49 LOTJ prevé que el magistrado-presidente, de oficio o a instancia de la defensa, decida la existencia o inexistencia de prueba de cargo sobre los hechos que se imputan, o sobre la insuficiencia para fundar la condena de alguno de los acusados (la prueba de cargo es la única idónea para desvirtuar la presunción de inocencia); la consecuencia de tal previsión es que el magistrado-presidente puede disolver el jurado dictando sentencia absolutoria motivada, impidiendo que el jurado delibere y llegue a igual o distinta conclusión.

En la formulación del objeto del veredicto se detectan problemas de orden práctico como la complejidad en la proposición del veredicto sobre los hechos; la indefinición en el planteamiento del veredicto; la influencia del magistrado-presidente por las instrucciones que pudiera verter sobre cuestiones jurídicas discutibles, y el sistema de mayoría divergente según se trate de hechos favorables o desfavorables. Como uno de los temas de mayor preocupación se destaca, además, la complejidad que plantea la circunstancia de que el jurado deba pronunciarse, en sentido global, sobre la inculpabilidad o culpabilidad del acusado, término ambiguo y de complejos matices difícilmente asequible para jueces legos. Se cuestiona también la solución que ofrece la LOTJ en el caso de que tenga lugar una crisis decisoria del jurado. Así frente a la previsión legal que sólo contempla expresamente la posibilidad de devolución del acta al Tribunal del Jurado en caso de contradicción entre el veredicto de "culpabilidad" y los hechos declarados probados, se sugiere que el término "culpabilidad" se entienda en sentido amplio, extendiéndose también al veredicto de inculpabilidad.

En cuanto a la conformidad entre partes, prevista en varios momentos procesales por la LOTJ se aconseja se produzca antes de constituirse el jurado. Por la todavía escasa andadura de la institución se pone de relieve la falta de un criterio homogéneo en las cuestiones organizativas del jurado $y$, en cuanto al fundamental tema del régimen de recursos se critica, básicamente, el que se limite la apelación a una serie de motivos tasados, cuando hubiera sido preferible una mayor ampliación o flexibilidad de los mismos, como demuestra el hecho de que, en la práctica, las Salas de lo Civil y Penal de los Tribunales Superiores de Justicia hayan tendido a un conocimiento pleno en segunda instancia del objeto del enjuiciamiento en dicho proceso. 
Fuera del informe del Consejo General del Poder Judicial quedan otras consideraciones que redundan en la revisión del modelo. De una parte, no se ofrece -apartándose de los precedentes anglosajones ajustados al jurado puro- a las partes y al Ministerio Fiscal, la posibilidad de elegir que una concreta causa por delito inicialmente competencia del Tribunal del Jurado, pueda ser enjuiciada por éste o por un tribunal de jueces profesionales, con lo que se configura un «automatismo procedimental" de difícil encaje con el artículo 117 de la Constitución. De otra parte, la competencia objetiva del jurado respecto de determinados delitos de escasa complejidad para el juez profesional implica poner en marcha toda la parafernalia de la ley (selección del jurado con sus sorteos, notificación a los seleccionados, vista para las excusas, resoluciones correspondientes, posibles nuevos sorteos, constitución del jurado, infraestructura de transporte, manutención, alojamiento, protección e indemnizaciones, celebración del juicio, emisión del veredicto, recursos, etc.) que aseguran una dilación para el asunto y un coste notable (se calcula entre 200.000 y 300.000 pesetas diarias), dada la estadística judicial en dicha clase de delitos.

Por otro lado, el Juez de Instrucción primero y el Magistrado Presidente después, han de "ajustar su agenda" a tales causas, con el efecto popular que comportan tanto mediático como de atención a tantas personas, los treinta y seis iniciales seleccionados por sorteo y los nueve jurados finales, con sus muchas veces inevitables secuelas familiares, de salud o profesionales que se suceden en el tiempo que va desde el momento inicial del sorteo hasta que emiten el veredicto, varios meses, por lo que debe prestárseles un tiempo y unos recursos de personal de la oficina judicial que van en detrimento de la marcha de los demás asuntos, que constituyen la inmensa mayoría, y que afectan a muchísimos más ciudadanos que las causas por jurado, cuyo número representan por ahora en torno al 1 por 100 del total de asuntos incoados en un año.

Tampoco se comprende que ser jurado, esto es, participar en la Administración de Justicia a través de dicha institución, se configure como un deber al que se anudan tan importantes sanciones económicas como las previstas en la LOTJ, cuya cuantía supera a la de muchas faltas. La función de jurado, tal como la establece la Constitución, no puede considerarse ni como deber ni como derecho-deber ya que el texto constitucional sólo habla como tales del trabajo, los deberes militares o de la contribución a las cargas financieras del Estado.

La LOTJ ha traspasado el mandato constitucional en este aspecto, olvidando que los poderes del Estado emanan del pueblo y los ciu- 
dadanos pueden participar en ellos o abstenerse, pues todo derecho político, y la participación en un poder del Estado, lo es en grado sumo, constituye un ejercicio de libertad, valor jurídico supremo del ordenamiento constitucional, que poderes y ciudadanos deben respetar. Javier Marías en las páginas de El País escribe que obligar a ser jurado, se quiera o no, representa una imposición injustificable, un abuso de autoridad y un atentado a la dignidad de la persona.

Por fin, de los distintos problemas que la actual LOTJ plantea, el más grave quizá sea el suscitado por el denominado "veredicto de culpabilidad o inculpabilidad", previsto como función de los jurados en el artículo 3.2 de la Ley. El problema estriba en que no obstante la atribución legal de semejante pronunciamiento a los jurados resulta imposible determinar cual sea el verdadero contenido $y$ significado del veredicto de "culpabilidad o inculpabilidad":

a) No parece que "culpabilidad" signifique aquí lo que tal expresión representa en el Derecho Penal sustantivo como elemento del delito.

b) Tampoco parece que "culpable», en veredicto del jurado sea, algo así como autor del hecho. $Y$ no parece posible porque la material intervención que el acusado haya tenido ya estará determinada, en cuanto hecho descrito objetivamente, por el jurado al sentar y fijar los. hechos probados.

c) Podría decirse que el veredicto de "culpabilidad" es un juicio negativo de reproche. Pero si éste es de carácter humano o ético, o social, no puede condicionar el que jurídicamente corresponda hacer bajo el principio de legalidad. Entonces ¿qué significa?

A la vista del texto legal parece que se identifica el veredicto de culpabilidad o inculpabilidad con una especie de mandato de condena o de absolución que a la vista de los hechos declarados probados formula el jurado al Juez de Derecho. Entonces se evidencia lo absurdo del sistema porque la condena o la absolución sólo es posible como una deducción derivada, no directamente de unos hechos concretos, sino del imperativo legal que resulta de la norma jurídica en que tales hechos se subsumen. Por lo tanto carece de sentido que el jurado además de establecer los hechos extienda su decisión a un veredicto de culpabilidad. Lo lógico es que, estableciendo los hechos, tal y como el jurado lego decida que han ocurrido, su misión termine en su fijación, por lo demás esencial, ya que esto es lo único que no precisa conocimientos jurídicos. Será luego el juez técnico quien sobre esos hechos aplique el Derecho, dentro de los términos exigidos por el principio acusatorio y decida la procedencia jurídica (no social, ética o política) 
de condenar o absolver. La condena o absolución, no son actos de voluntad aunque sea ésta popular; es deducción jurídica obtenida con arreglo a la ley. $Y$ esto es una conquista fundamental de nuestra civilización. De hecho el veredicto de culpabilidad que se recoge en la LOTJ supone incluso una regresión en lo que ha sido la evolución del jurado habido en España; porque sabido es que, precisamente por las dificultades que suponía el que el jurado se pronunciara sobre "culpabilidad", el Decreto de 22 de septiembre de 1931 incluyó este punto como una de las modificaciones a introducir, para su eliminación, en el régimen de la Ley de 1888.

Supongamos que unos hechos determinados son imputados a un acusado como delictivos. $Y$ supongamos que tales hechos son ciertos y han sido probados íntegramente, entendiéndolo así el jurado lego. Lógicamente tras declararlos probados emitirá un veredicto de culpabilidad. Entonces ¿qué sucede si los hechos no cumplen jurídicamente las exigencias típicas del delito en cuestión, tal y como el juez de Derecho interpreta ese tipo penal? ¿Debe condenar convirtiendo artificialmente en delictivo un comportamiento que a su juicio es atípico, sólo porque el veredicto es de culpabilidad, o puede no condenar en tal caso? Se dirá que la LOTJ en su artículo 63 prevé la posibilidad de que el juez técnico devuelva el acta del veredicto al jurado, entre otros casos, «cuando los diversos pronunciamientos son contradictorios, bien los relativos a los hechos declarados probados entre sí, bien el pronunciamiento de culpabilidad respecto de dicha declaración de hechos probados". No está claro que así sea sin forzar la interpretación del precepto.

Pero donde la gravedad del problema se hace más patente aún es en el actual artículo 67 LOTJ. Cuando el veredicto de "culpabilidad" no es coherente con los hechos declarados probados cabe la devolución del veredicto a los jurados para que subsanen la contradicción (artículos 63 y 64), en los términos ya explicados. Sin embargo, y esto es especialmente grave, cuando la contradicción se produce entre los hechos probados y un veredicto de «inculpabilidad", el artículo 67 LOTJ no prevé devolución alguna sino que dispone imperativamente que "el Magistrado Presidente dictará en el acto sentencia absolutoria del acusado a que se refiere, ordenando, en su caso, la inmediata puesta en libertad».

Por lo tanto, en este supuesto se evidencia que el tal veredicto sobre la inculpabilidad no es otra cosa que un mandato indiscutible de absolución. $Y$ un mandato que debe cumplir necesariamente el magistrado-presidente, aun cuando los hechos declarados por el jurado probados sean "legalmente" típicos, exista autoría penal, y no 
concurra causa alguna de exención de la responsabilidad. Con ello queda consagrado por esta vía indirecta, en sede de Ley procesal, el principio de oportunidad no reglada en nuestro Derecho Penal al menos en el ámbito competencial propio de esta ley presidía nuestro ordenamiento penal.

Los problemas expuestos derivan, en último término, de la previsión legal contenida en el artículo $61.1 \mathrm{~d}$ ), que, abandonando el sistema de la íntima convicción, apuesta por un sistema de libertad valorativa razonada que supone la concreta determinación de los actos de prueba, la sujección a tales actos de la formación de la convicción y el razonamiento de la valoración de aquéllos, no debiéndose olvidar que el jurado español delibera sin la presencia del magistrado-presidente. Resulta difícil creer que los jurados legos, sin la debida asistencia técnica realicen no solamente valoraciones de hecho, sino una verdadera actividad intelectual de subsunción normativa que puede desvirtuar el principio de presunción de inocencia, salvando problemas tales como la elaboración de la prueba preconstituida o anticipada, la ilicitud de prueba y sus consecuencias sobre otras, el estudio y la acreditación de los elementos normativos del tipo penal, etc.

\section{CONSIDERACIONES FINALES}

No se pone en cuestión el jurado, sino su regulación, las soluciones ofrecidas. Aquí se ha mostrado una no desdeñable muestra de ellas, en gran parte apuntadas ya durante la tramitación parlamentaria de la LOTJ (Cfr. Ley Orgánica del Tribunal del Jurado. Trabajos Parlamentarios. Cortes Generales. Madrid, 1996). La revisión de la ley en las líneas apuntadas sin duda contribuiría a un mejor funcionamiento de esta institución siempre discutida, pero entendemos que no basta con la reducción del número de delitos atribuido a su competencia, la respuesta adecuada a la cuestión de la conexidad o a los recursos procedentes, la previsión de la exclusión del conocimiento del jurado de determinado delito cuando las partes así lo resuelvan, etc., sin olvidar su excesivo costo. El futuro del jurado pasa por el cambio de modelo en pro del escabinado en el que, como escribió F. Pacheco a fines del siglo XIX ( La Ley del Jurado. Revista de Legislación y Jurisprudencia. Madrid, 1888) el tribunal formado por los jueces profesionales y los escabinos uexamina toda la cuestión planteada en una causa, y así estima las pruebas como califica los hechos que de ellas resulten, $y$ aplica la ley a esos resultados". Se da pleno cumplimiento al mandato constitucional del artículo 125 pero también al del artículo 120.3 que requiere que todas las sentencias sean motivadas. Con el jurado puro no re- 
sulta posible, como contundente y reiteradamente ha subrayado nuestro Tribunal Supremo en más de una decena de sentencias, $y$ entre otras, las de 11 de marzo, 30 de mayo y 6 de octubre de 1998. Por todas, la conclusión de Montero Aroca y Gómez Colomer (Comentarios a la Ley del Jurado. Aranzadi, Pamplona, 1999) es tan clara como contundente al justificar la publicación de su obra a los tres años de entrada en vigor de la LOTJ: "expresar el deseo de todos los autores de que estos comentarios contribuyan a la necesaria modificación de la Ley del Jurado, a ser posible, transformándole en Ley de Escabinado, a la altura de los países de nuestro entorno cultural de mejor tradición jurídica.

La evaluación de la Ley del Jurado a la luz del trámite de la casación penal permite, por lo demás, de las cincuenta sentencias dictadas por nuestro Alto Tribunal, extraer dos grandes conclusiones:

- existencia de un altísimo porcentaje de veredictos revocados, con la inmediata consecuencia en la mayor parte de los casos, de repetición del juicio, con la consiguiente exigencia de formar un nuevo jurado y reproducción de todos los trámites procesales desde entonces, incluidos los hipotéticos nuevos recursos.

- concreción de las decisiones revocatorias del Tribunal Supremo en una serie de cuestiones que se concreten, además de en la falta de motivación del veredicto, en la confección incorrecta de éste, en la contradicción fáctica determinante del fallo, en problemas de individualización de la pena, en problemas de expresión de las mayorías necesarias y en la errónea apreciación de las circunstancias modificativas.

\section{NOTA BIBLIOGRÁFICA}

Cardona Minguez, E.: El jurado. Su tratamiento en el Derecho Procesal español. Dykinson. Madrid, 2000.

Fairen Guillén, V.: "La participación de los ciudadanos en la Administración de Justicia: los Tribunales de Jurados y de Escabinos", en Estudios de Derecho Procesal, Civil, Penal y Constitucional. T.I. Edersa. Madrid, 1983.

Gimeno Sendra, V.: "El artículo 125 de la Constitución», en Constitución y Proceso. Tecnos. Madrid, 1988.

Gimeno Sendra, V.: "La segunda reforma urgente de la Ley del Jurado". Poder Judicial núm. 39, 1996.

Gisbert GisberT, A.: "Sobre el desarrollo del art. 125 de la Constitución: ¿Tribunal de Jurados o Escabinato?». Revista General de Derecho, núm. 481482 (octubre), 1984.

Gómez Colomer, J.L.: «El Jurado. Estatuto jurídico y designación del juez legon. El Tribunal del Jurado. VV.AA. Cuadernos de Derecho Judicial, núm. monográfico, 1995. 
Gutiérrez Alviz Armario, F. y Moreno Catena, V.: "Comentario al artículo 125 de la Constitución", en Alzaga VILlaAmil, O.:(dir.). Comentarios a las Leyes Políticas. T. IX. Edersa. Madrid, 1987.

López Muñoz y LARRAz, G.: "La justicia penal por Jurado". Revista de Derecho Procesal Iberoamericana, núm. 1, 1980.

López MuÑoz y LARRAZ, G.: "Bases para una nueva Ley del Jurado". Revista General de Legislación y Jurisprudencia, núm. 252, 1982.

López Muñoz y Larraz, G.: “Decálogo del Jurado español». Revista General de Derecho núm. 511. 1987.

Lorca Navarrete, A. M.a: Manual del Tribunal del Jurado español. Dykinson. 3." ed. Madrid, 1997.

MARÍN GAMEZ, J.A.: Elementos para una revisión crítica del Jurado en España. UNED. Jaén, 1997.

Martin Ostos, J.: "Algunas consideraciones sobre el jurado". Anuario Facultad de Derecho Universidad de Extremadura núm. 3 (1984-1985).

Martín Pallín, J.A.: "El Jurado, ¿otra forma de justicia?". Poder Judicial núm. 45 (enero-marzo), 1997.

Martín Pallín, J.A. (dir.): Manual del Jurado. Abella-El Consultor de los Ayuntamientos. Madrid, 1996.

Montero Aroca, J. y Gómez-Colomer, J.L.: Comentarios a la Ley del Jurado. Aranzadi. Pamplona, 1999.

Pedraz Penalva, E.: "El Jurado como vía de participación popular". La Ley núms. 3509 y 3510, 1994.

Pedraz Penalva, E.: "Sobre la participación popular en la justicia penal». Revista Canaria de Ciencias Penales núm. 4, 1999.

Pérez-Cruz Martín, A.J.: "En defensa del escabinado". La Ley núm. 3679, 1994.

Prego de Oliver Tolivar, A.: "La Ley del Jurado». Deliberación núm. 10, 1994.

Prieto-Castro, L.: "El Jurado". Tapia, febrero, 1983.

Serrano Alberca, J.M.: "Comentario al artículo 125 de la Constitución", en GaRRIDO FAlLA, F.: Comentarios a la Constitución. Cívitas. 2. ${ }^{a}$ ed. Madrid, 1985.

Soriano DIAZ, R.: "Argumentos y líneas programáticas de un Jurado de escabinos en España". Poder Judicial núm. 15, 1985.

Urbano Castrillo, E.: "Jurado. ¿Derecho o deber?". La Ley núm. 4445, 1997.

V.AA.: El Jurado sí: pero ¿cómo y cuando? CGPJ. Madrid, 1982.

V.AA.: El Poder Judicial. Instituto de Estudios Fiscales. Madrid, 1983.

VV.AA.: Jornadas sobre el Jurado. Servicio de Publicaciones de la Universidad de Extremadura. Cáceres, 1989. 